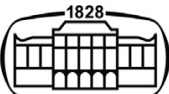

AKADÉMIAI KIADÓ

\title{
Singularity measurement in the Cyber-physical and intelligent robot systems laboratory
}

\section{TIMOTEI ISTVÁN ERDEI* • () and GÉZA HUSI}

\section{International Review of Applied Sciences and Engineering}

$11(2020) 2,82-87$

DOI:

$10.1556 / 1848.2020 .20001$

(c) 2020 The Authors

\section{ORIGINAL RESEARCH}

\section{PAPER}

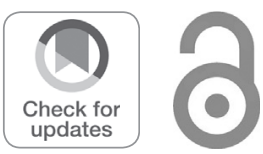

Departmentof Mechatronics Engineering, University of Debrecen, Doctoral School of Informatics Debrecen, Debrecen, Hungary

Received: May 25, 2019 • Accepted: September 12, 2019

Published online: June 30, 2020

\begin{abstract}
In the building mechatronics research centre of University of Debrecen, Faculty of Engineering, a new laboratory has been designed, named "Cyber-physical and intelligent robot systems laboratory". The possibility to design and test unique and platform-independent systems was among the main goals, hoping that the system itself and its advancements may later be used in manufacturing industries as well.

Fulfilling the needs of "Industry 4.0 " is a challenging task, as it requires every single device (e.g. industrial robots) to be connected to the same network, where they may be monitored and controlled. However, there are some factors that limit this, such as the periodical "instability" that some machines have, caused by singularity points.

The following material studies these so-called singularities of a KUKA KR5 industrial welder robot placed in a robot cell, from an engineering viewpoint.
\end{abstract}

\section{KEYWORDS}

KUKA, singularity, robot cell, degrees of freedom, simulation

\section{INTRODUCTION}

In some industries, the training of engineers can be a rather involved process. During training, students must become familiar with devices and environments that they might encounter in that specific industry. It's essential that they get ample practice in such an environment, and to this end, a robot cell was designed, which consists of a KUKA KR5 welder robot and its three platforms built around it (Fig. 1).

The robot itself has been the subject of many earlier researches at the Department of Mechatronics Engineering [1] including topics of control and Augmented Reality [2].

While these robots are known for their reliability, there exists a point called "singularity point". If the robot passes this point during its operation, it either performs an emergency stop, or operates in an unexpected manner [3]. This problem can be traced back to the complex mathematical background of the robot's controlling software.

The occurrence of these singularity points leads to mistakes in the robot's movement, which leads to faulty items being manufactured, causing increased costs.

Of course, the question of singularity is an extensive one. By establishing a reliable measurement method, we may acquire a valuable groundwork for further research.

\section{SINGULARITY}

The usage of robot manipulators is widespread in industries. Thanks to their multi-joint structure, they can perform welding, boring, material handling, and painting tasks, depending on the currently equipped tool or gripper. 


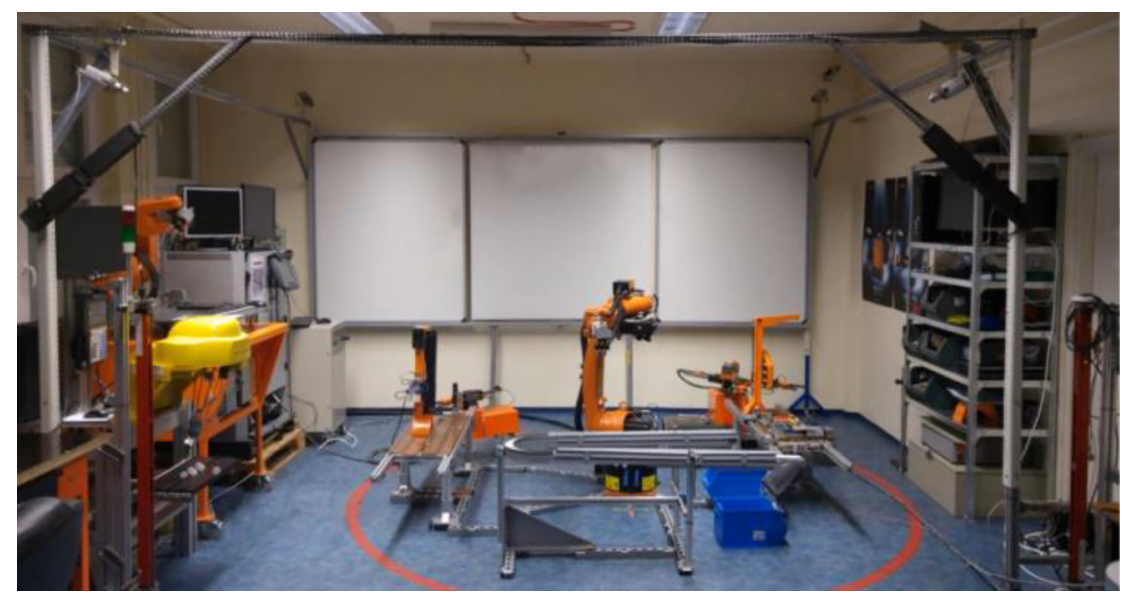

Fig. 1. Cyber-physical and intelligent robot systems laboratory

However, regardless of the task itself, kinematical singularity is present as a risk factor, as the joint configuration has a deficient Jacobi matrix assigned.

Because the Jacobi matrix cannot be inverted in the given singularity it leads to high joint speeds, which can lead to the injury of any operators present.

Singular configuration is such a configuration, where it cannot be moved by just any speed vector [4].

The Descartes speed control equation:

$$
\dot{q}={ }^{0} \mathbf{J}_{\theta}^{-1}{ }^{0} \dot{x}_{n}
$$

If it is valid for the connection between $A$ and $B$, ${ }^{\mathbf{A}} \mathbf{T}_{\mathbf{B}}=[\underline{\mathrm{n}} \mathrm{o} \underline{\mathrm{a}} \mathrm{p}]$, then the speed vector in "A" system can be transformed to " $\mathrm{B}$ " system, as:

$$
B_{\dot{x}}={ }^{B} \mathbf{J}_{A}{ }^{A} \dot{x}_{A}
$$

In which case, the Jacobi matrix is as follows [5].

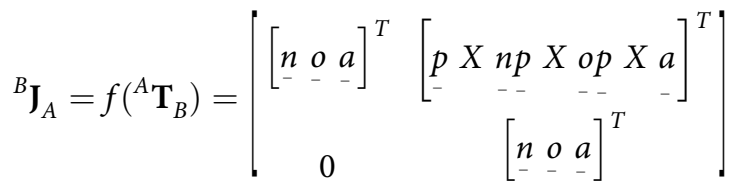

Studies of singularity are made more difficult by the fact that there is no universal solution to the problem, and that these events are often unpredictable. However, the loss of degrees of freedom has a negative effect on any given task. This problem gets worse if an assembly line works with multiple robots with this same issue: every step must be designed with careful consideration of the singularity points. As such, they must be monitored continuously to prevent damages.

\section{DESIGN OF A MEASURING SYSTEM}

The root cause of singularity can be traced back to inverse kinematics. However, studying this issue with conventional methods is not possible [6].
The complexity of this issue is partly due to the nature of the units themselves. Individual units are "Closed-Source": unlike "Open-Source" projects, there is no way to access or directly modify the robot's operating system, or its calculations.

Furthermore, the mathematical algorithms used during programming also varies between different models and manufacturers. We can only draw conclusion from the product, and more precisely, the errors themselves produced by the product. The entirety of the system is a "black box": we know our issued commands, and the result itself, but not how exactly said result was achieved.

While we cannot eliminate this problem, we can analyse the behaviour causing the singularity itself (Fig. 2).

Measurements were already made in previous studies which had to do with the KUKA KR5's singularity problem. However, these were only in an experimental stage, not to mention that the robot was not in its current, new environment [7].

During these tests, the previously mentioned KUKA KR5 robot was used. The main hardware components of it are the robot arm itself, the KRC2 control panel, and the Teach Pendant [8]. A teach pendant is a special controller used for programming industrial robots. Generally, it consists of various buttons and controls which are used to move the robot into the desired position. In the KR5's case, this

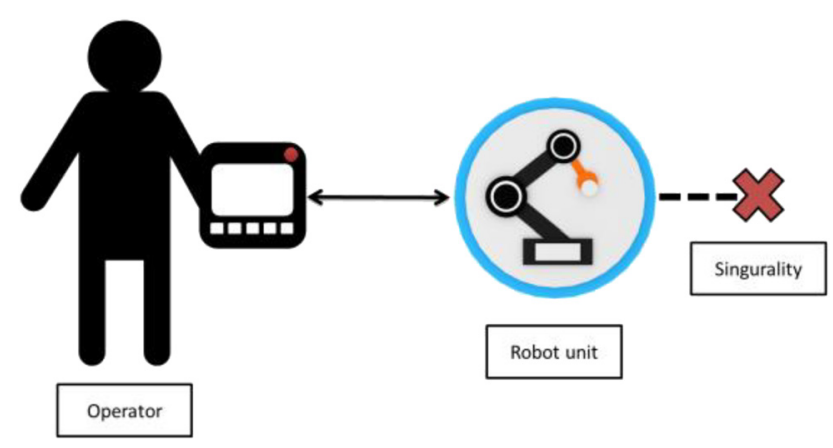

Fig. 2. Singularity during the robot's movement 
pendant houses multiple components, like user interface buttons, movement buttons, an input device called the " $6 \mathrm{D}$ mouse", a screen, and dead man's switches, which must be pushed with the right amount of force for the robot to operate during programming. This is one of the main safety features.

While controlling the machine, singularities are unpredictable. However, guiding it through one or more singularity points, we can observe the unexpected behaviour, and differences in movement.

As mentioned earlier, neither the exact algorithm, nor software used by the KRC2 platform is available to us, being a "Closed-Source" system. Because of this, we had to do the measurements indirectly.

An original measuring system was assembled for the indirect measurements, containing the following parts:

- KUKA robot's control system

- KUKA KR5 ARC robot arm

- Head unit containing a laser, an accelerometer, and an angular speed sensor (part of the fixed head unit was made using a locally developed CNC machine [9])

- Square pattern sheet

- Long exposure-time camera

- Netbook (for collection of acceleration data)

- Laptop (for recording coordinates)

Two methods were used in measuring the robot arm's deviation from a straight line. Points are recorded at the gripper, while at the same time, the given coordinates are also recorded, while it goes through the singularity.

As a safety feature, the robot immediately stops when it predicts that an upcoming point is a singularity point. As a workaround, the robot had to be moved in manual mode, at low speeds.

On the laptop, the computationally demanding robotcoordinate recording program was running. This software also gives immediate feedback by displaying current position on a $3 \mathrm{D}$ model of the robot, in real time. These coordinates were acquired from a connection between the control cabinet and the notebook. The used notebook was a Lenovo ideapad Z710 [10]. The choice fell on this laptop as it has an Nvidia GT840M with 2 GB DDR3 VRAM, and a Core i7 processor. Having a dedicated video card was crucial for running the mentioned 3D display. Earlier, a Dell Inspiron 1,018 was used, however, due to the hardware requirements using it was no longer viable [11].

The mentioned computer and the KUKA KR5 KRC2 was connected via UTP cable.

This laptop also handled data collection from the accelerometer, and the angular speed sensor. The sensor unit was connected to an Ardunio NANO [12] panel, which sends the I2C sensor's data through a USB connection for collection. The measuring head unit houses the laser, which used the sensor's power supply as well, due to its low power consumption. On Fig. 3, the measuring head unit can be seen in the coordinate system defined by the accelerometer and the speed sensor. The X, Y, Z coordinates point in the direction of positive acceleration values, while the angular

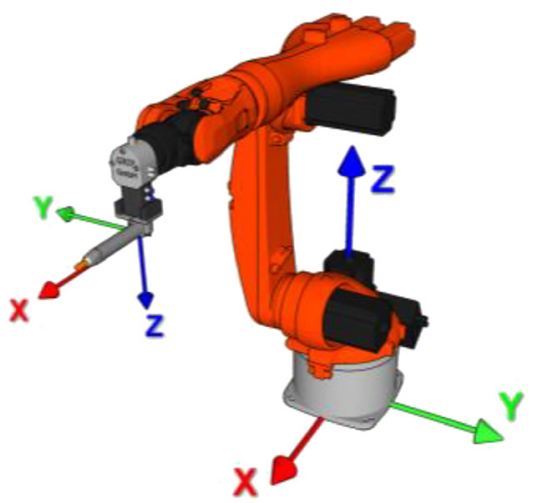

Fig. 3. Robot WORLD, and head unit coordinate systems

speed sensor measures rotational speeds along these axes. The measuring head unit is composed of the following components:

1. Head unit fastening points

2. Acceleration and speed sensors

3. Laser module

The acceleration and speed sensors are sensor based on MPU-6050 [13] MEMS [14] technologies. They can measure linear acceleration along three axes, and angular speed along the three axes. Their maximal update frequency (the rate of individual measurements) is up to $40 \mathrm{~Hz}$. The device has a built-in 16 bit Digital-Analogue converter.

The laser is a $650 \mathrm{~nm}$ wavelength red laser, with a performance of $5 \mathrm{~mW}$ [15]. This unit contains a diode creating the laser light, parallelising lenses (to create the point of light), and a power supply, to generate suitable power for the diode from a $5 \mathrm{~V}$ input voltage.

The central part, with the most important parameters, is the KUKA KR5 robot arm. The KUKA KR5 has six axes, with a workspace volume of $8.4 \mathrm{~m}^{3}$. Its gross weight is approximately $127 \mathrm{Kg}$.

The properties of the axes can be seen in the following Table 1 [8]:

\section{LASER MEASURING METHOD}

The next part of the measurement is drawing the robot's trajectory using a method called light painting [16]. First, a suitable camera's exposition time is set to a high enough

Table 1. Movement and speed range of axes [8]

\begin{tabular}{lcc}
\hline Axes & $\begin{array}{c}\text { Software limited range of } \\
\text { motion }\end{array}$ & $\begin{array}{c}\text { Maximum angular speed at } \\
\text { nominal load }\end{array}$ \\
\hline 1 & $+155^{\circ}$ & $154^{\circ} / \mathrm{s}$ \\
2 & $+65^{\circ}$ and $-180^{\circ}$ & $154^{\circ} / \mathrm{s}$ \\
3 & $+158^{\circ}$ and $-15^{\circ}$ & $228^{\circ} / \mathrm{s}$ \\
4 & $+350^{\circ}$ & $343^{\circ} / \mathrm{s}$ \\
5 & $+130^{\circ}$ & $384^{\circ} / \mathrm{s}$ \\
6 & $+350^{\circ}$ & $721^{\circ} / \mathrm{s}$ \\
\hline
\end{tabular}


value, in our case $30 \mathrm{~s}$. Then, while holding the camera steady, a bright point of light is moved. With its long exposure time, the camera records all these moving points of light, creating a single image of the trajectory itself.

Fig. 4 shows the positioning of the devices used for light painting. In order to ensure reproducibility, specific distances were marked, and recorded. These values can be seen in Table 2. From a top-down view, the measuring head's (Fig. 4 2.) axis is in line with the axis of the camera's lens (Fig. 4 4.). The robot arm's (Fig. 4 1.) distance was given relative to the square pattern sheet (Fig. 4, 3.).

The reference point of the measuring head was chosen to be the centre point of its two sensor's ICs, as this is where the sensors' axes cross each other. The tool centre point was assigned based on this point as well.

The distance between the scaled sheet and the laser unit was $2,000[\mathrm{~mm}]$.

The robot arm was returned to its HOME position before every measurement. Table 3 shows the individual angles of each axis.

The shown distance and angle values are used as a reference, to ensure that every measurement starts from the same position.

As a scale, a printed grid was used, with one-centimetre divisions. This was placed between the robot arm and the camera. Before the measurements themselves, the robot was moved horizontally in non-singularity trajectories, and the sheet was positioned to that. The setup's accuracy was checked with a test measurement.

Fig. 5 shows the test measurement, where the robot was moved by $100 \mathrm{~mm}$ in a straight line, outside of any singularity points. As expected, it didn't show any undesired behaviour.

The slight deviation from a perfect straight is explained by the KUKA KR5's position repeatability, which is (according to ISO 9283): $\pm 0.04 \mathrm{~mm}$.

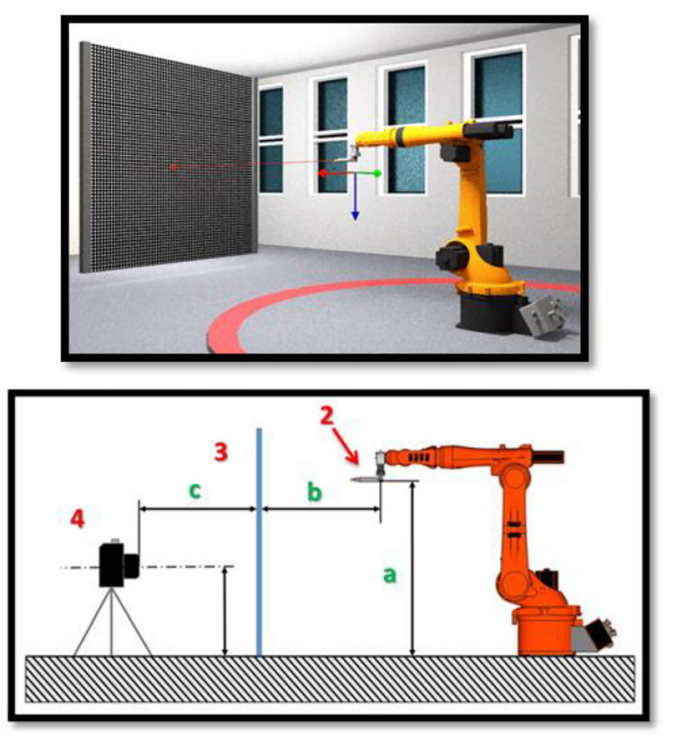

Fig. 4. Light painting measurement
Table 2. Marked dimensions of Fig. 4

\begin{tabular}{lcccc}
\hline Mark & A & B & C & d \\
\hline Distance $[\mathrm{mm}]$ & 1,050 & 2,000 & 1,620 & 900 \\
\hline
\end{tabular}

Table 3. Axis angles at HOME position

\begin{tabular}{lcccccc}
\hline Axis & 1 & 2 & 3 & 4 & 5 & 6 \\
\hline Angle $\left[^{\circ}\right]$ & $0^{\circ}$ & $-90^{\circ}$ & $90^{\circ}$ & $0^{\circ}$ & $0^{\circ}$ & $0^{\circ}$ \\
\hline
\end{tabular}

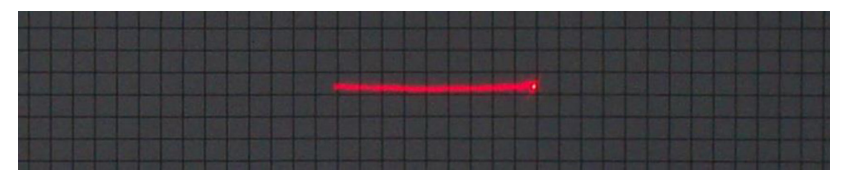

Fig. 5. Test measurement

On Fig. 6, the assembled and equipped measuring head can be seen. Unlike the 3D model, the laser module is not visible, as it was built into the head's chassis. This was done to achieve the needed mechanical stability. On its left, the accelerometer, the speed sensor, and the laser module's power wires can be seen.

\section{SINGULARITY MEASUREMENTS}

In the kinematic system of the KUKA robot, three singularity types are defined [3]. These are the following: the overhead singularity, the extended position's singularity, and
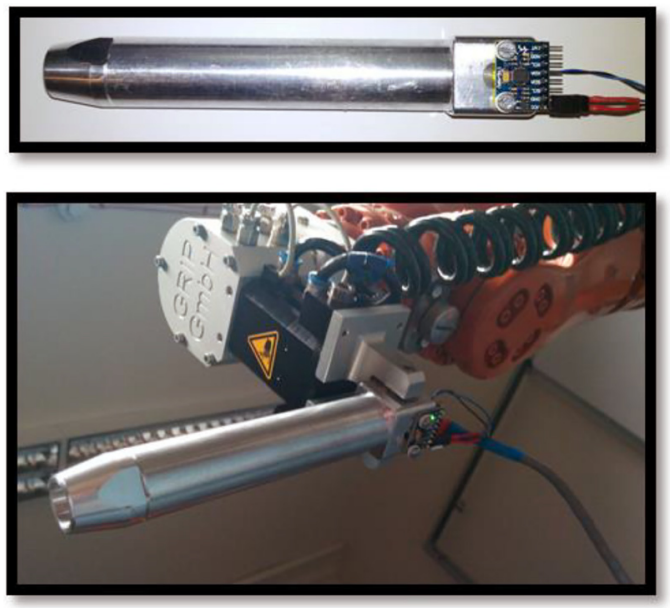

Fig. 6. Assembled and equipped measuring head

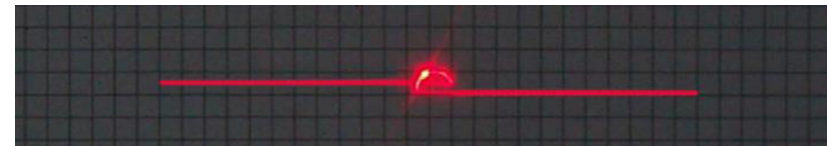

Fig. 7. Wrist singularity 


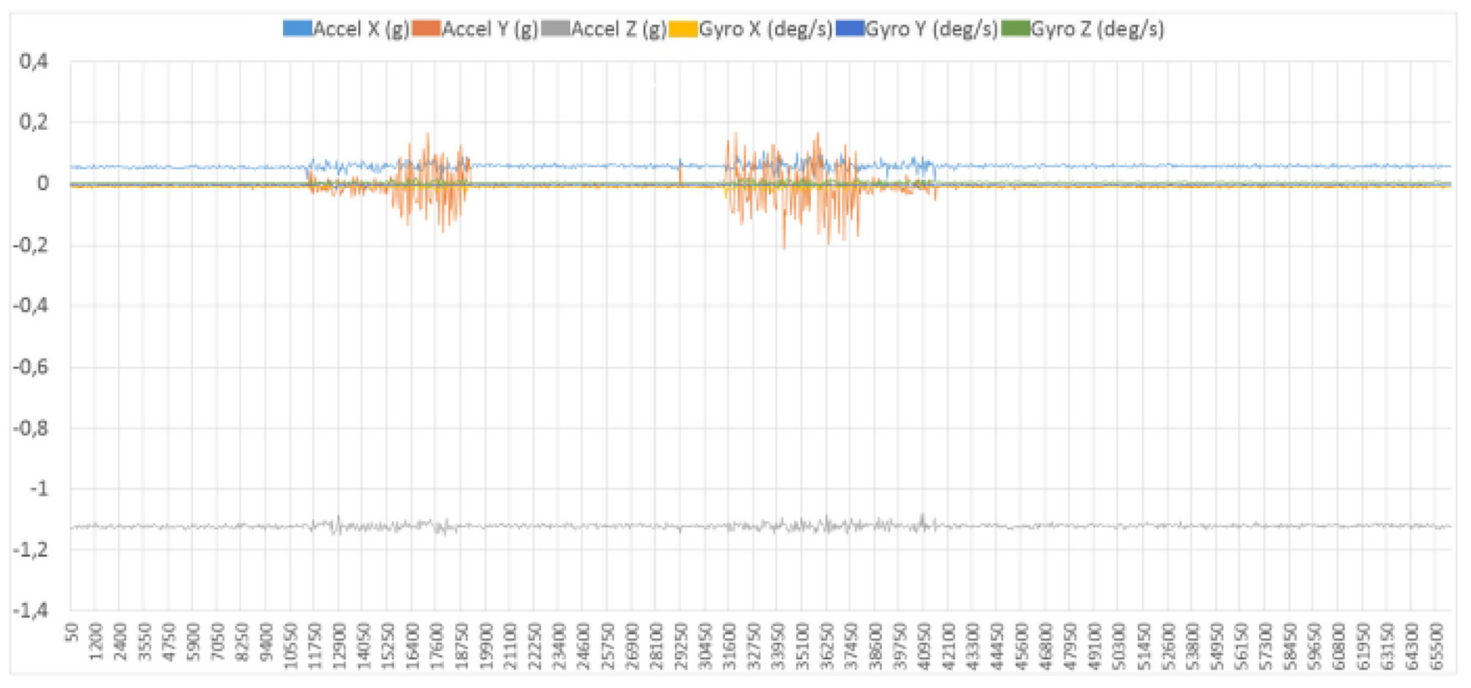

Fig. 8. Graphical representation of wrist singularity measurement data

Table 4. Coordinates

\begin{tabular}{lccc}
\hline & $X[\mathrm{~mm}]$ & $Y[\mathrm{~mm}]$ & $\begin{array}{c}\mathrm{Z} \\
{[\mathrm{mm}]}\end{array}$ \\
\hline Starting point & 965,002 & 0.009 & 1120,016 \\
Endpoint & 864,998 & 0.008 & 1116,225 \\
\hline
\end{tabular}

the wrist's singularity. During these measurements, the wrist's singularity was studied.

Due to the mechanical structure of the KUKA KR5, wrist singularity happens when the rotational axes of axis A4 and axis A6 are the same. In the robot's HOME position, these axes are on the same axis.

Before the measurement, the robot was moved along $\mathrm{Y}+$ axis by $120 \mathrm{~mm}$ in manual mode, using the WORLD coordinate system. During the measurement, the robot was moved in a way that it arrives at a final coordinate of $\mathrm{Y}=-120 \mathrm{~mm}$.

As a result, at $0 \mathrm{~mm}$ the robot's A4 and A6 axes coincide, and singularity happens (Fig. 7).

During singularity, the measuring head's accelerations are also recorded, which are processed by the Lenovo laptop mentioned earlier. The collected data is presented as a graph, where $\mathrm{X}$ axis is time [ms], $\mathrm{Y}$ axis is the linear acceleration, and angular speed (Fig. 8).

On the graph, both positive and negative deviation can be seen. The reason for this is that the measuring head was moving along its own $\mathrm{Y}$ axis, however, A5 stopped before rotating over. This produced acceleration along the $\mathrm{Y}$ axis.

During this rotation, no actual acceleration or angular speed was present, but after the rotation, it continued moving along the $\mathrm{Y}$ axis, resulting in another jump in both values. This can be observed on the graph as well. This event took a total of $9.2 \mathrm{~s}$ during movement.

As the KUKA KR5 robot arm was moved in the WORLD coordinate system, no emergency shutdown happened at the singularity, and the arm could leave the singularity point.
The coordinates of these notable points can be seen in Table 4. (relative to the HOME position).

\section{SUMMARY}

In the Cyber-physical and intelligent robot systems laboratory, a unique measuring system was developed for the KUKA KR5 industrial welder robot, capable of singularity measurements. In addition to position, and deviation data, visual data can also be collected, which may provide valuable information regarding a robot's behaviour at the chosen singularity point, and eventually, help solve these issues.

With the light painting solution, a "Closed-Source" system's measuring tasks were realised in a stable, and costeffective way.

The created system was tested using one singularity scenario, further work is required to collect data on other singularity types, which collectively may lay the groundwork to further studies in the future.

\section{ACKNOWLEDGEMENTS}

Hereby I would like to thank Dr. Husi Géza for his helping suggestions, and I would like to thank Molnár Zsolt and Nwachukwu C. Obinna, who actively participate and help in the ongoing research and development.

\section{REFERENCES}

[1] G. Husi, P. T. Szemes, E. Dávid, and T. I. Erdei, "Building Mechatronics Research Centre as energy aware Intelligent Space," in Industrial Electronics Society - IECON 2013 - 39th Annual Conference of the IEEE, 01/2013. 
[2] T. I. Erdei, Z. Molnár, N. C. Obinna, and G. Husi, "Cyber physical systems in mechatronic research centre," in MATEC Web of Conferences 126, 01006, Annual Session of Scientific Papers IMT ORADEA, 2017, https://doi.org/10.1051/matecconf/201712601006.

[3] G. Husi, "Position Singularities and Ambiguities of the KUKA KR5 Robot,” Int. J. Eng. Technol., vol. 1, no. 1, 2015.

[4] ELTE 11EA, "Térbeli infinitezimális izometriák," [Online]. Available: http://web.cs.elte.hu/ szeghy/files/alkmodul11EA.pptx. [Accessed: 1904 2019].

[5] R. P. Paul, B. Shimano, and G. E. Mayer, "Kinematic control equations for simple manipulators," IEEE Trans. Syst. Man Cybern., vol. 11, pp. 449-55, June 1981.

[6] R. P. Paul, Robot Manipulators: Mathematics, Programming, and Control. The MIT Press, 1981, ISBN: http://doi.org/978-0-262-16082-7.

[7] M. Zsolt, N. C. Obinna, T. I. Erdei, G. Husi, "KUKA KR5 ipari robotkar szingularitásának vizsgálata” - RIIM - Debreceni Egyetem - 30.01.2018.

[8] KUKA Roboter Group, "KR 5 Arc - Specification," [Online]. Available: https://www.kuka.com/-/media/kuka-downloads/ imported/48ec812b1b2947898ac2598aff70abc0/spez_kr_5_arc_en. pdf. [Accessed: 1010 2017].

[9] M. Zsolt, E. T. István, A. Husam, H. Géza, "Saját CNC prototípus rendszer mint IoT eszköz," in Müszaki tudományos közlemények
7, Kolozsvár, Erdélyi Múzeum Egyesület (EME), 2017, pp. 295-8, ISBN: http://doi.org/978-963-449-018-0.

[10] Lenovo, "Lenovo Z710," [Online]. Available: https://www3.lenovo. com/us/en/laptops/lenovo/z-series/z710/. [Accessed: 0110 2017].

[11] Dell, "Dell Inspiron Mini 1018," [Online]. Available: http://www. dell.com/en-us/shop/cty/pdp/spd/inspiron-mini1018. [Accessed: 2010 2017].

[12] Arduino, "Arduino NANO," [Online]. Available: https://store. arduino.cc/usa/arduino-nano. [Accessed: 0509 2017].

[13] InvenSense, "MPU-6000 and MPU-6050 Product Specification," [Online]. Available: https://www.invensense.com/wp-content/ uploads/2015/02/MPU-6000-Datasheet1.pdf. [Accessed: 0209 2017].

[14] N. C. Obinna, S. A. Afghan, T. I. Erdei, Z. Molnar, P. Szemes, and G. Husi, "LabVIEW Motion Planning and Tracking of an Aerial Robotic System: Dynamic Simulation of the Robot's Embedded Vibratory MEMS Gyroscope," https://www. researchgate.net, https://doi.org/10.13140/RG.2.2.17163. 18720, 2017.

[15] HESTORE, "LASM-987," [Online]. Available: https://www. hestore.hu/prod_10035542.html. [Accessed: 2011 2017].

[16] Digital Photography School, "Light Painting," [Online]. Available: https://digital-photography-school.com/light-painting-part-onethe-photography/. [Accessed: 3009 2017]. 